Waste and Resource Management Volume 167 Issue WR3

Extending product lifetimes: a reuse network for ICT hardware

Dietrich, Becker, Nittka et al.
Proceedings of the Institution of Civil Engineers

Waste and Resource Management 167 August 2014 Issue WR3

Pages 123-135 http://dx.doi.org/10.1680/warm.13.00024 Paper 1300024

Received 17/07/2013_Accepted 28/04/2014

Keywords: business/European Union (EU)/recycling \& reuse of

materials

\title{
Extending product lifetimes: a reuse network for ICT hardware
}

Johannes Dietrich MSC

Researcher, Technische Universität Berlin, Berlin, Germany

Frank Becker

Project Manager, Technische Universität Berlin, Berlin, Germany

Thomas Nittka Dr.-Ing

Manager, tricom GmbH, Berlin, Germany

Matthias Wabbels

Manager, tricom $\mathrm{GmbH}$, Berlin, Germany

Dan Modoran Eng.

Partner, Greentronics, Alexandria, Romania

Cristian Aionesei Eng

Partner, Greentronics, Alexandria, Romania

Gerhard Kast Dipl.-Ing.(FH)

Chief Executive Officer, Umweltanalytische Produkte GmbH, Cottbus, Germany

Ian David Williams BSC, PGCE, PhD, CChem, MRSC, MCIWM, FHEA Professor, Centre for Environmental Sciences, Faculty of Engineering and the Environment, University of Southampton, Southampton, UK

\section{Tony Curran BSC, MRes, PhD}

Research Fellow, Centre for Environmental Sciences, Faculty of Engineering and the Environment, University of Southampton, Southampton, UK

Emilia den Boer Dr.-Ing.

Assistant Professor, Waste Technology and Land Remediation, Institute of Environment Protection Engineering, Wroclaw University of Technology, Wroclaw, Poland

Bernd Kopacek MSC

Managing and Research Director, Austrian Society for Systems Engineering and Automation (SAT), Vienna, Austria

Sabine Schadlbauer

Researcher, Austrian Society for Systems Engineering and Automation (SAT), Vienna, Austria

\section{Jorg Musterle}

Researcher, Austrian Society for Systems Engineering and Automation (SAT), Vienna, Austria

This paper examines how a network of small/medium-sized enterprises was developed to enable reuse and resource conservation in the information and communications technology sector by exchange of used equipment over a resource exchange internet platform. The network's effectiveness and potential for expansion is also examined. The results demonstrate that it is possible and in many cases economically viable to increase the reuse stream of equipment and to extend the network's activities to a European level. The expectation of doubling the amount of traded appliances within the network was greatly exceeded. The successful development of technical, legal and financial guidance led to its incorporation into an accredited industry guideline.

\section{Introduction}

The EU has drawn up a list of 14 key raw materials that are needed to maintain our economy and lifestyle (EC, 2010). The list highlights a group of key rare/scarce metals for which global production is concentrated in a few countries. The restricted supply base combined with the relatively low political stability ratings for some major producing countries significantly increase risk to supply. The list highlights economically important metals that are at risk of supply disruption, including rare earth metals, platinum group metals and metals such as indium.

These key rare/scarce metals are best conserved by reuse or recycling from waste electrical and electronic equipment (WEEE) (Öko-Institut, 2011). Significant quantities of such products are disposed of by means of landfill and incineration or are stockpiled in homes and businesses at the end of their operational lifetime. This situation results in tremendous dissipation and probable loss of key metals (if products are disposed of) or a potential reservoir for a circular economy (if products are stockpiled). The large quantity of high-tech WEEE and stockpiled electrical and electronic equipment (EEE) has led to a focus of attention on

the variety of materials they contain, many potentially harmful to humans and the environment

- how these materials are handled, generated and dispersed around the globe, often from the EU to developing countries

ways in which they can be brought safely and cost effectively back into the value chain.

The information and communications technology (ICT) sector uses considerable quantities of natural resources and contributes significantly to greenhouse gas (GHG) emissions and fresh water utilisation. In 2009, around 1 billion mobile phones and 306 million PCs and laptops were sold and shipped worldwide, leading to $\sim 40 \mathrm{Mt}$ of obsolete EEE, $\sim 51 \mathrm{Mt}$ of carbon dioxide emissions and $\sim 400$ million $\mathrm{m}^{3}$ fresh water use (HOP, 2013; 
Waste and Resource Management

Volume 167 Issue WR3
Extending product lifetimes: a

reuse network for ICT hardware

Dietrich, Becker, Nittka et al.
Kuehr and Williams, 2007; N24, 2013). The collection and appropriate treatment of used EEE and WEEE are crucial steps towards conservation of key resources in the ICT sector.

Project Zerowin (Towards zero waste in industrial networks; www.zerowin.eu) is an ambitious EU-funded project researching - and trialling by means of case studies with industrial partners methods and strategies to eliminate the wasteful consumption of resources in key industrial sectors in Europe, primarily by means of the formation of industrial networks. The project is based on the vision reported by Curran and Williams (2012).

In the Zerowin case study reported in this paper, a network of small and medium enterprises (SMEs) and micro-enterprises was developed to enable reuse and resource conservation in the ICT sector through the exchange of used products by means of a resource exchange platform (RXP). The activities were based on an existing legal entity, the regionally focused ReUseComputer eingetragener Verein (e.V.) (henceforth known as the ReUse ICT network), based in Berlin, Germany. The goals of the case study were to increase the reuse stream of ICT equipment and extend the activities of the ReUse ICT network from a regional to European level. Initially, the ReUse ICT network consisted of 21 partner organisations, comprising one wholesaler, three refurbishers, four retailers, eight ICT service and consulting firms, two environmental organisations, one academic body, one creative sector company and one private individual. The ReUse ICT network offered its members not only a reuse business opportunity, but also other fields of activity for environmental protection and social engagement. By offering low-cost high-quality ICT equipment for customers, the network effectively increased the availability of affordable ICT technology in society, helping to bridge the socalled 'digital divide'. In the EU, such reuse networks have also been established in Belgium, the Netherlands and Austria.

This case study covers activities starting when a used ICT product enters the ReUse ICT network, considers all the necessary refurbishment processes and ends when the product is sold to the second user (reuse). Quantitative enhancement is provided as a consequence of increasing the number of used products (sale/rental) and services traded between ReUse ICT network partner organisations and customers. The useful lifecycle of the reuse products is assumed to double by using high-level refurbishment procedures. A quality scheme has been developed and is binding for all ReUse ICT network members (Figure 1) unless they have already developed their own quality process that meets the criteria of the ReUse ICT quality scheme; in this case, new members may keep their own process after joining the network.

In order to define a system boundary to allow assessment of the case study's achievements, a desktop PC, a laptop and a measurement unit (consisting of two dataloggers that can be used for measuring weather data, soil moisture, etc.) were selected as indicator products traded within the RXP. The functional unit was defined as one piece of indicator product with a lifecycle of one use phase. In the baseline scenario, the useful lifecycle of an ICT indicator product ends after one use phase; it is considered waste afterwards and it is either disposed of or recycled. One use phase is assumed to be 4 years (desktop PC, laptop) or 10 years (measurement unit). In the improved scenario, ICT appliances are not considered waste after the first use phase but traded between business customers and refurbishers from the ReUse ICT network over the RXP. According to experiences from the ReUse ICT network, it is assumed that the lifecycle of ICT appliances can be doubled when high-level refurbishment is implemented according to the ReUse ICT network's quality scheme.

\section{Experimental methods}

Four approaches (with associated methods) were developed, as summarised in Table 1. Approaches A-C addressed increasing reuse of ICT equipment whereas approach $\mathrm{D}$ addressed extending the activities of the ReUse ICT network from a regional to European level.

\subsection{Approach A: Enhancement of reuse ICT business opportunities}

An RXP was developed and optimised as a technological basis for ICT product exchange. The RXP is a platform to share information about products for reuse and recycling that are available from a specified network member. It is directed at individual enterprises willing to exchange their used products and components to achieve economic and ecological benefits. The RXP enables a request to be made for a specific product or material, tracking and take-back of ICT products between businesses, and includes an inventory function with technical information about a product, its condition and current owner. Surveys and technical focus groups were used to collect the specification requirements of the RXP and data formats used by existing platforms that deal with reuse products. The platform is available in English and German. The RXP is comparable to eBay, but there are significant differences. The RXP

targets businesses as opposed to private individuals

offers an inventory function that allows product tracking, take-back and optimal maintenance of the product

allows product requests, which may stimulate higher activity in the network and enhance the exchange of higher quality reuse products

does not use an auction process for purchasing transactions.

New members within the ReUse ICT network were secured by means of standard networking activities. A marketing 


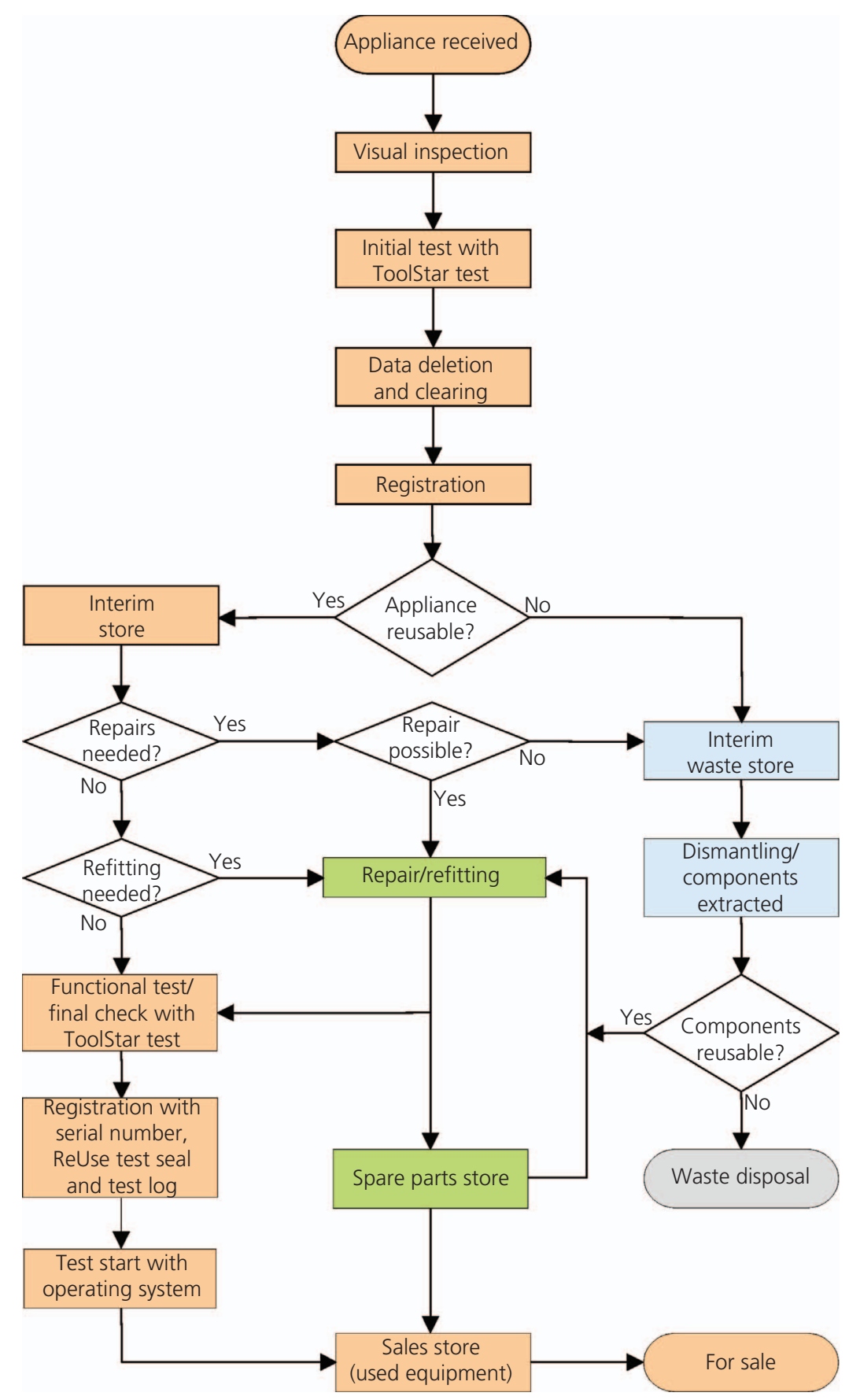

Figure 1. ReUse ICT network - quality scheme and quality control label

strategy was developed to increase RXP throughput. This was informed by a literature review, surveying ICT distributors/retailers for sales data, and surveying consumers (320 youths aged 17-25) for their purchasing behaviour with respect to reuse products.
A feasibility study for offering product rental and a data service instead of selling the ICT product itself was performed by estimating the economic performance of comparative scenarios that would highlight the dis/advantages to businesses of services instead of sales. In addition, rental prices for 
Enhancement of reuse ICT business opportunities and operations

Test the transferability of the ReUse ICT network concept to other product categories

Test the transferability of the ReUse ICT concept to other regions
RXP

Develop and optimise an RXP that enables tracking, refurbishment and reuse of used ICT equipment

A2 Acquisition

A3 Marketing strategy

Set up ReUse ICT network marketing strategy

A4 Service instead of sales

Compile feasibility study 'Service instead of sales'

A5 Take-back

Compile feasibility study 'Take-back'

B1 Technical guidelines

Develop technical guidance for reuse ICT operations

B2 Cost assessment

Compile a cost assessment of the refurbishment process

C1 Comparative study

Compile a comparative study: reuse of wood offcuts

\section{C2 Extension of the RXP}

Enable and test the trade of other product categories over the RXP

Market survey

Compile market surveys about the reuse ICT sector in three European countries: D1a expert survey in Austria; D1b expert survey in Romania; D1c expert survey in UK

Table 1. Overview of the main approaches and methods used in this case study

measurement devices from 11 companies were compared by net price of the new product. The price categories used were $€ 500$ (range $€ 0-500$ ), $€ 1500$ (range $€ 501-1500$ ), $€ 3000$ (range $€ 1501-3000$ ) and $€ 5000$ (range $€ 3001-5000$ ).

It has been found that ICT products are frequently purchased at the beginning of a research or educational project at universities and, without taking stock, often stored at the university when the project ends. This is not only a waste of resources as other projects could make use of these appliances instead of purchasing new equipment, but it also offered a business opportunity for the ReUse ICT network. Therefore, a feasibility study for take-back of ICT products at a university was performed by estimating the number, type and purchase value of ICT appliances by means of a survey. The survey was conducted at Brandenburgische Technische Universität Cottbus (BTU) in Germany between November 2011 and September 2012. In addition, Umweltanalytische Produkte GmbH conducted 'inventory inspections' at Berlin Institute of Technology, Dresden Institute of Technology and Finsterwalde Institute of Former Mining Landscapes in 2011 and at Cottbus Institute of Technology, Wroclaw University of Technology and Saxonian Institute of Agriculture, Geology and Environmental
Protection in 2012. These inspections aimed to identify instruments that were still working or that could be taken back, repaired and reused.

\subsection{Approach B: Reuse best-practice guidance}

A technical guidance document designed to improve business opportunities in the reuse ICT sector concerning practical operations was designed in collaboration with industry. It was developed to determine processes and quality criteria for the refurbishment and reuse of used EEE and is considered fundamental to the ReUse ICT network's activities and quality scheme. As well as technical guidance, financial information is necessary to improve business opportunities for the reuse of ICT appliances. The costs of labour for computer maintenance and component exchange were obtained by surveys within workshops arranged during two regional meetings of the ReUse ICT network in May and June 2012.

\subsection{Approach C: Transferability of the ReUse ICT network concept to other product categories}

In order to test if the concept of enabling reuse and resource conservation in the ICT sector by exchange of used products 
could be replicated in other sectors, an assessment of a regionally based project for resource conservation of wood offcuts was conducted. The project, entitled 'hikk - Holz im Kreativkreislauf' (Wood in creative cycles (http://hikk.mixxt. de)) ran from 2009 to 2012 and was co-funded by the European Social Fund. The goal of the project was to produce and market small pieces of furniture and accessories from wood offcuts that were sourced from within the network. The feasibility of resource conservation activities was assessed in terms of potential GHG emission savings, savings of waste materials and job creation potential. The following two scenarios were compared.

- Scenario 1 - wood offcuts were declared as waste, incinerated and thermally recovered in a regional incineration plant.

- Scenario 2 - wood offcuts were collected, processed and used for furniture production.

The RXP was further tested by trading other used industrial products, including several models of measurement equipment and mobile phones. In addition, a regional industrial network was identified that was willing to exchange products and byproducts and test the RXP. In 2011 and 2012, two telephone surveys were carried out with Netzwerk Großbeerenstraße e.V., a Berlin-based network of $\sim 50$ SMEs and microenterprises from different industrial sectors. The surveys involved asking company chief executive officers about their willingness to utilise the RXP.

\subsection{Approach D: Transferability of the ReUse ICT network concept to other regions}

The transferability of the concept for product reuse to other EU regions was investigated through a literature review, discussions with experts and an in-depth study in the UK. In the UK study, conducted between May 2011 and October 2012, the RXP was introduced to a charity operating in south London and a private WEEE recycling company operating near Portsmouth.

\section{Results}

\subsection{Enhancement of ReUse ICT network business opportunities}

The RXP was successfully implemented. The outputs from the surveys and technical focus groups enabled the successful delivery of the specification requirements and suitable data formats for the RXP. The environmental impacts of the transactions facilitated by the platform are estimated and displayed on the RXP homepage (www.trxp.eu); these include avoided waste and savings of GHG emissions and fresh water utilisation. Other functions developed and implemented include uploading quality test reports, user manuals and data sheets

printing reuse labels

data export to other platforms

- smartphone application.

The RXP's initial use statistics (to 27 March 2013) show that the number of users more than doubled (to 46); 726 products were posted since the beginning of the case study and 63 products were sold. ICT equipment transactions include (status as of 27 March 2013) 20 laptops, 24 PCs, three Delta-T DL2eloggers, five relative humidity/air temperature sensors, ten copper/constantan thermocouples and a Datahog2. It is estimated that these transactions (not including sensors and thermocouples) produced environmental savings of

$487 \mathrm{~m}^{3}$ of fresh water (PCs, $288 \mathrm{~m}^{3}$; laptops, $163 \mathrm{~m}^{3}$; dataloggers, $36 \mathrm{~m}^{3}$ )

$11550 \mathrm{~kg}$ carbon dioxide equivalent (PCs, $6408 \mathrm{~kg}$; laptops, $5100 \mathrm{~kg}$; dataloggers, $42 \mathrm{~kg}$ )

$369 \mathrm{~kg}$ of waste (PCs, $271 \mathrm{~kg}$; laptops, $88 \mathrm{~kg}$; dataloggers, $10 \mathrm{~kg})$.

New members were successfully introduced to the network, enabling the throughput of used ICT equipment to increase from 30000 appliances to around 280000 items. In addition, the ReUse ICT network marketing concept was successfully set up, based on corporate social responsibility principles.

Table 2 shows that, over the long term, offering a data service is the most profitable business model (of those studied). It also illustrates that, for some products (e.g. the WS-GP1 weather station), generating a profit by offering a rental service can only be achieved if benefits for resale of the used appliance are included in the calculation.

The results from offering product rental instead of selling an ICT product were less clear cut and showed only marginal profitability, especially when rental may only occur in practice for short periods of time. When calculating a rental service offer, it is important to be aware of additional costs that influence the profitability of a product rental service (Table 3).

Results from the feasibility study for take-back of ICT products at BTU Cottbus between 2004 and 2011 are shown in Table 4. Table 5 shows the annual allocation and disposition of WEEE at BTU Cottbus. Note that minor deviations in the sum of purchase prices in Tables 4 and 5 occur due to different data sources. The figures show that from 2004 to 2011, devices with an average total original value of around $€ 1968$ 000/year were given away, either for recycling/disposal or for reuse. Within that time period, 6561 units were disposed of as WEEE, 232 were sold through the VEBEG platform 
Costs for customer

Hardware costs

Consumables (relative humidity sensor elements)

Insurance

Delivery, training

Costs for data service

Costs for customers' staff for maintenance and data evaluation/month

Total costs/36 months

Direct payment to vendor

Costs for company

Buy/produce weather station, consumables

Costs for data service (GSM costs, server, etc.) Costs for installation, dismantling, collection Interest rates for prepayment of instruments and services (8\%/year)

Profit/36 months

Possible selling price for used weather station, $75 \%$ of list price after 3 years

Total profit after 3 years

Profit for another renting/service period

instead of selling the used station
3700

$\begin{array}{ccc}\begin{array}{c}3700 \\ 384\end{array} & \begin{array}{l}89 \text { (3204/36 months) } \\ \text { Included }\end{array} & \text { Included } \\ \text { Not available } & \text { Included } & \text { Included } \\ \text { Option: } 640 & \text { Included } & - \\ - & - & - \\ 100 & 100 & 6084 \\ 7684 & 6804 & 6084 \\ 4084 & 3204 & -3300 \text { (incl. GSM } \\ -2894 & -2894 & \text { modem, solar panel) } \\ - & -640 & -480 \\ - & -848 & -640 \\ - & -1178 & -1061 \\ 1190 & 2275 & 603 \\ - & 1597 & 3225 \text { (incl. GSM modem, } \\ 1190 & 2800 & \text { solar panel) } \\ 0 & & 3828 \\ & & 5604\end{array}$

Table 2. Comparison of different sale and service scenarios over a period of 3 years

(federal liquidation platform) for reuse and 142 were given to charity. In 2006-2007, approximately $10 \%$ of obsolete appliances were sold, whereas in 2010 and 2011 no appliances were sold for reuse. This is probably due to a 2009 directive from the Ministry of Finance of Brandenburg, Germany that made it complicated and time consuming to give away used appliances for reuse. Tables 4 and 5 provide typical examples of the quantities and types of reusable ICT and measurement equipment identified by means of the inventory inspections carried out at several universities. Some of the appliances identified by means of the inspections were subsequently entered into the RXP database.

\subsection{Reuse best-practice guidance}

Technical, legal and financial guidance was successfully developed in collaboration with industry. The document now forms part of industry guideline VDI 2343 issued by Verein Deutscher Ingenieure e.V. VDI 2343, entitled 'Recycling of electronic and electric devices', addresses legal, technical and economic as well as ecological and social aspects (Brüning, 2012). The key messages from the developed guidance are as follows. (a) High-value ICT investment goods represent value for other market segments and regions even after their lifecycles have exceeded the depreciation time.

(b) The economic feasibility of reuse measures depends on a number of factors including

(i) product type

(ii) costs related to collection, refurbishment and marketing/distribution

(iii) product innovation

(iv) sales factors (e.g. region, demographics, competition with other new and used products)

(v) availability, technical lifetime, quality and condition of appliances

(vi) potential savings for product development and material purchase

(vii) availability of product information and market data

(viii) the existence of 'green' public procurement policies.

(c) National and regional legislation can affect operational practices. 
Costs for registration and administration work: control of rental time; costs for delayed payments; costs for packing material; costs for communication; costs for information management (location of product, use of product, product return, etc.)

- Maintenance and repair after return of product

- Shipping

Table 3. Cost factors for product rental service
Purchase of product from manufacturer

Installation, maintenance, repair as long as product is with customer

Storage

- Travelling (for repair, maintenance) if necessary (d) Reuse offers a business opportunity for specialised companies. Original equipment manufacturers (OEMs) do not normally focus on refurbishment as this activity would be limited to their own products and would compete with their core business. Additionally, at present only small take-back quotas are achieved by manufacturers.

(e) Rental/leasing and sale offer different opportunities to control the product stream.

(f) Regional reuse networks offer logistic symbiosis potentials with negotiable economic compensations and implementation of joint quality and marketing concepts.

Tables 6 and 7 respectively list the average estimated labour times required for exchanging computer parts and maintaining the appliance in the refurbishment process.

\subsection{Energy recovery and transferability of the ReUse ICT network concept}

The assessment of resource conservation of wood offcuts revealed that, in $2011, \sim 5244 \mathrm{~m}^{3}$ of scrap wood accumulated in 125 carpentries located in Berlin-Pankow. In scenario 1, the wood is subsequently used for energy recovery. Assuming an equivalent of $245 \mathrm{~kg}$ carbon dioxide $/ \mathrm{m}^{3}$ of chipboard (average density $660 \mathrm{~kg} / \mathrm{m}^{3}$ ) used for furniture, the possible savings of GHG emissions are $\sim 107000 \mathrm{~kg}$ carbon dioxide/month. Based on the annual throughput of the biomass power plant and the number of employees, the employment effect of the energy recovery of scrap wood in Berlin-Pankow is $\sim 0.7$ employees/year.

In scenario 2 , it is theoretically possible that 52 units of 'Lotta Rest' multi-functional furniture cubes could be built out of $1 \mathrm{~m}^{3}$ scrap wood. However, in practice only $50 \%$ of the

\begin{tabular}{|c|c|c|c|c|}
\hline Group & Specification & Number & $\begin{array}{l}\text { Average time from } \\
\text { purchase to disposal: years }\end{array}$ & Purchase cost: $€$ \\
\hline A & Batteries & 52 & $7 \cdot 47$ & 47042 \\
\hline B & Burners (DVDs, CDs) & 98 & $8 \cdot 13$ & 42370 \\
\hline D & Printers, plotters & 892 & $10 \cdot 80$ & 1030738 \\
\hline $\mathrm{F}$ & Hard disk drives (HDDs) & 449 & $7 \cdot 87$ & 161744 \\
\hline G & Extension boards (graphics, docking, audio) & 192 & $8 \cdot 78$ & 152112 \\
\hline K & Network components & 304 & $9 \cdot 08$ & 734060 \\
\hline $\mathrm{L}$ & Disk drives & 300 & $9 \cdot 69$ & 304299 \\
\hline M & Monitors (CRT, TFT) & 1196 & $8 \cdot 75$ & 865527 \\
\hline $\mathrm{N}$ & Notebooks, laptops, handhelds, etc. & 274 & $8 \cdot 04$ & 640223 \\
\hline$P$ & PCs, servers & 2261 & $9 \cdot 48$ & 6860701 \\
\hline Q & Storage devices (USB sticks, RAM) & 358 & $7 \cdot 47$ & 204981 \\
\hline$S$ & Scanners & 77 & $9 \cdot 81$ & 77331 \\
\hline W & Workstations & 203 & $10 \cdot 68$ & 2638500 \\
\hline$X$ & Others & 279 & $9 \cdot 65$ & 406707 \\
\hline Total/average & & 6935 & $8 \cdot 98$ & 14166286 \\
\hline
\end{tabular}

Table 4. Take-back potentials - results from survey at University BTU Cottbus (Dünnwald, 2012) 


\begin{tabular}{lcccrr} 
Year & Number of items & $\begin{array}{c}\text { Number deemed as } \\
\text { WEEE }\end{array}$ & $\begin{array}{c}\text { Number of items } \\
\text { reused }\end{array}$ & $\begin{array}{c}\text { Number of items } \\
\text { given to charity }\end{array}$ & Purchase cost: $€$ \\
\hline 2004 & 109 & 94 & 9 & 6 & 368000 \\
2005 & 600 & 582 & 14 & 4 & 1240000 \\
2006 & 686 & 621 & 65 & 0 & 2329000 \\
2007 & 1264 & 1091 & 109 & 64 & 1946000 \\
2008 & 887 & 700 & 16 & 16 & 2333000 \\
2009 & 740 & 1594 & 0 & 19 & 2032000 \\
2010 & 1604 & 1024 & 0 & 21 & 2293000 \\
2011 & 1045 & 6561 & 232 & 142 & 1601000 \\
Total & 6935 & & & 14142000
\end{tabular}

Table 5. Take-back potentials - annual allocation and disposition of WEEE at University BTU Cottbus, 2004-2011 (Dünnwald, 2012)

correctly sized scrap wood is suitable for furniture production. Thus, from the $37.5 \mathrm{~m}^{3}$ of suitable scrap chipboard sourced from the carpentry shops of Berlin-Pankow, 975 multifunctional furniture cubes could be produced every month. In practice, the production time per cube is $\sim 20 \mathrm{~min}$. Assuming that a market for the furniture cubes could be established, this would lead to an output of 11700 cubes/year in $3900 \mathrm{~h}$. Based on the typical hours of a full-time job, this is equivalent to $2 \cdot 25$ jobs. The $0 \cdot 7$ jobs for energy recovery of the remaining scrap wood must be added at the end of the furniture's lifetime, and hence scenario 2 could result in $\sim 2.95$ full-time jobs.

In terms of the trading of other products, the RXP worked properly with respect to data entry. However, it proved difficult to sell used mobile phones for a fixed price. It appears that most used mobile phones traded in the EU are auctioned either in large lots (directly, with potential buyers worldwide) or as single items (mostly through eBay). Due to its market penetration, eBay has colossal access to potential customers in this product sector and hence it will be difficult for the RXP to compete.

\subsection{Transferability of the ReUse ICT network concept to other regions}

In Austria, from 29 $000 \mathrm{t}$ of ICT products sold in 2010, 57\% were collected and $0 \cdot 94 \%$ refurbished and reused (EAK, 2011). Discussions with experts in Austria indicated that, in the business market, more than $50 \%$ of ICT equipment is leased. At

\begin{tabular}{|c|c|c|c|}
\hline \multirow{2}{*}{ Part to be exchanged } & \multicolumn{3}{|c|}{ Average (range): min } \\
\hline & PC & Notebook & Datalogger \\
\hline Opening of housing & $1 \cdot 5(1-2)$ & $7 \cdot 5(5-10)$ & N/A \\
\hline HDD & $3 \cdot 5(2-5)$ & $6(2-10)$ & N/A \\
\hline Main memory & 2 & 10 & N/A \\
\hline Housing & 60 & 90 & N/A \\
\hline Mainboard & 20 & 60 & 15 \\
\hline $\mathrm{PCl}$ card & 1 & $\mathrm{~N} / \mathrm{A}$ & N/A \\
\hline Cooling element & $12 \cdot 5(5-20)$ & 30 & N/A \\
\hline Display & N/A & 30 & N/A \\
\hline Keypad & N/A & 15 & N/A \\
\hline Power supply unit & $12 \cdot 5(5-20)$ & N/A & N/A \\
\hline Capacitor, soldered & 30 & 30 & N/A \\
\hline BIOS chip, soldered & $30(20-40)$ & N/A & N/A \\
\hline Fan & $12 \cdot 5(5-20)$ & 30 & N/A \\
\hline Batteries & $3 \cdot 5(2-5)$ & $22 \cdot 5(15-30)$ & $2 \cdot 5(2-3)$ \\
\hline
\end{tabular}

Table 6. Estimated average labour time and range for exchange of IT equipment parts 


\begin{tabular}{lccc} 
& & & Average (range): min \\
\cline { 2 - 3 } Action & PC & Notebook & Datalogger \\
\hline Replace or install additional HDD & $3.5(2-5)$ & $7.5(5-10)$ & N/A \\
Clean inside & $3.5(2-5)$ & $7.5(5-10)$ & N/A \\
Clean outside, basic cleaning & $5.5(1-10)$ & $3(1-5)$ & 10 \\
Delete and check HDD & Fixed price, 20 & Fixed price, 20€ & N/A \\
Functional test & $7.5(5-10)$ & $7.5(5-10)$ & $22.5(15-30)$ \\
System reimaging & $20(10-30)$ & $20(10-30)$ & 30 (calibration) \\
Install Windows XP without service package 1-3 & $60(50-70)$ & $65(50-80)$ & N/A \\
Install Windows 7 without service package 1 & $30(20-40)$ & $35(25-45)$ & N/A \\
Install Linux with basic programs & 25 & 25 & N/A
\end{tabular}

Table 7. Average estimated labour time and range for maintenance of used equipment

their end of use, the EEE is typically returned to the leasing company, data are erased and any necessary repair/refurbishment is completed (mostly outside Austria (Germany, Netherlands, eastern Europe)) and then the equipment is sold to developing countries.

If the equipment has not been leased, most Austrian companies tend to give ICT equipment to their employees to use domestically (normally through representatives of workers' unions) either free of charge or for a small donation to the workers' union. The companies are typically aware that this creates problems in terms of data security (data are often not properly erased) and software licensing, but management feel it is more important to do something positive for the workers' union to safeguard future relationships.

Companies that do not hand equipment over to their employees typically donate their end-of-use ICT equipment to schools, social projects, etc. Reuse within private households is common practice, but there is no study about quantities in Austria. From experience from within the Zerowin consortium, most of these 'household' products enter the WEEE stream, are donated to charities or are handed over to informal collectors (see the TransWaste project (www.transwaste.eu)). This constitutes a business opportunity for formalised collection within Austria and subsequent resale.

The National Agency for Environmental Protection in Romania (http://www.anpm.ro) suggested that, from 2006 (when EU legislation was implemented) to 2010, approximately $847668 \mathrm{t}$ of EEE was put on the market. In the same period, the total amount of WEEE collected was around $91553 \mathrm{t}$, giving a collection rate of $10 \cdot 8 \%$. In 2010, around $151316 \mathrm{t}$ of EEE was sold and $26246 \mathrm{t}$ of WEEE was collected (collection rate of $17 \cdot 4 \%$ ). Of this collected waste, $24 \cdot 6 \%$ was ICT equipment. The reuse ICT industry in Romania is currently not as well developed as in other EU countries. Possible explanations are that

ICT equipment is generally used for longer than 5 years by its owners and is therefore of poorer quality than in other EU countries

the economic crisis has affected the country severely

most companies (with a small number of exceptions) involved in waste management generally do not have the technical capacity and skills to enable reuse on a significant scale

the distributors of used electronics prefer to take their products from developed markets such as UK and Germany, using specialised websites (e.g. www.diablos computer.ro).

One partner in the Zerowin consortium, Greentronics, manufactures and remanufactures multi-function printing equipment for SMEs. Greentronics has developed several charity projects with large companies and banking institutions. Part of the WEEE collected from these institutions is remanufactured and then donated to various organisations, community groups, etc. Greentronics has proposed a Zerowin-style industrial network to representatives of leading manufacturers in the Romanian market; the proposal has been greeted with enthusiasm, demonstrating that there is potential to transfer the concept to relatively underdeveloped EU countries.

Consultation with reuse organisations in the UK resulted in several suggestions for improvements in the trade of ICT equipment using the RXP, as summarised in Table 8. The UK study provided an example of how a legal framework may be 
Pool resources and share services with other like-minded charities

- Achieve industrial symbiosis (not just simple prolonging of lifecycle)

Enable local materials search and connect large recycling plants with like-minded reuse organisations

- Provide the possibility for automatic input of data into the RXP (instead of manual data entry)

- Use more graphics to display information, especially on the dashboard

- Manufacturers' parts numbers need to be an option for data entry

RXP needs to exploit markets that are not already exploited by other organisations

Improve the RXP through comparison with existing platforms such as Adisa, PowerSource and Tradeloop

- The RXP should not have subscription fees

- Translate the platform into English (and when possible add other languages)

- Make additional product details (such as date of production or model type) available to the customer

- Link the RXP to universities and colleges around Europe so that students can purchase cheaper refurbished ICT equipment

- Insert a monitoring system that provides useful data about the refurbished product (such as service life, technical issues or details)

- Include individuals as a source type of ICT
- Overall aim of the RXP

Fostered by local search and by clustering local companies within user groups

- Fostered by local search and by clustering local companies within user groups

- Already provided by data-import function and smartphone application

- Video tutorials and resources-saved-counter have been inserted that add graphical information

- Can be inserted in input boxes 'serial number' or 'description'

- An inventory function has been programmed that allows the identification of unused products within big organisations such as universities and hospitals; this opportunity has not yet been used

- The RXP offers a unique set of functions for business-to-business material exchange (such as inventory, resources-saved-counter and local search)

- Already implemented

- RXP fully translated into English; other languages will be added on demand

- Unspecific: category, model, description/state, serial number, ISRI/EWC waste codes, pictures, price, manual can be indicated or uploaded

- Already implemented at Technische Universität Berlin and Brandenburgisch Technische Universität Cottbus

- Already implemented

There are no restrictions for the registration of individuals

Table 8. Suggested improvement potentials for RXP (from a UK survey) and measures undertaken

complied with when trading used ICT equipment in a relatively developed EU country.

A waste management licence issued by the Environment Agency is required if the company deals with waste.

- Compliance with the restriction of hazardous substances directive, the WEEE directive, the trans-frontier shipment of waste regulations 2007 and the UK plan for exports and imports of waste is required and checked.

- Dismantling companies in England and Wales need an exemption, as stated within paragraph T11 of the environmental permitting regulations 2010 .
There are no legal barriers preventing organisations renting items out of the UK.

\section{Discussion}

\subsection{Enhancement of Reuse ICT network business opportunities}

Through integration of a broad range of products and materials, the design and development of the RXP enhanced the ReUse ICT network both qualitatively and quantitatively. It is clear that the RXP could be a significant tool for exchange of materials and could substantially increase the number of 
organisations involved in the reuse of ICT (and other) products. As the RXP is a web-based tool, it readily allows an extension of the ReUse ICT network from a regional to European level, and there is evidence from developed and underdeveloped EU countries to support this. Nevertheless, broad introduction of the RXP into European markets is a process that will need further efforts and research in future. In particular, it will be necessary to make high-level refurbishment and reuse more accepted in European society, to increase significantly the number of products traded through the RXP and to market the platform successfully.

In terms of offering product rental and a data service instead of selling ICT products, the feasibility of the service offer depends on the customer type. For example, universities and research institutes normally need instruments for long periods of time, so renting is probably not a sensible option for them, although it might be economically viable to select a data service. Consulting and engineering offices are more likely to be interested in a rental service as they often work on short-term projects. Carefully thought-out logistical and operational procedures and economic calculations that relate to an individual business case need to be accomplished in order to offer a service that is economically sensible for both the customer and the service company.

Regulations at national or international level can significantly impact economic feasibility. For example, the German Ministry of Finance has recently changed the depreciation time for estimating the book-keeping value of ICT devices from 60 months to 36 months. This reduces the book value of ICT devices to only $€ 1$ after 3 years. In contrast, the BFL IT index (www.bfl-it-index.de) estimates the book value to be $34 \%$ of the purchase price after 3 years or $24 \%$ after 4 years. Applying the BFL IT index approach to the ICT equipment from BTU Cottbus, a cashback from sales of obsolete equipment of up to about $€ 400000 /$ year is possible. Even if $75 \%$ of the appliances were scrapped because of damage or for other reasons, $25 \%$ of appliances that were used for up to 4 years would provide an annual cashback of around $€ 100000$. Scaling this up to a national level, the economic potential of selling used ICT appliances from universities can be estimated to be approximately $€ 40$ million in Germany. Consequently, the business opportunity for the reuse of ICT equipment from European universities is considered high, although it must be acknowledged that the full potential is unlikely to be realised once factors such as performance limitations and the influence of fashion are taken into account.

Public collection facilities represent a technical barrier for enhanced reuse and recycling in ICT networks as they do not provide damage-free collection and are not willing to hand over material to refurbishers. Retailers in the ReUse ICT network therefore source used goods for resale mainly from wholesalers in southern Germany, which in turn source used ICT equipment from large businesses such as insurance companies and public enterprises. An economic as well as ecological improvement option is to establish cooperation along the collection, refurbishment and sales chain.

Furthermore, in some countries, such as Romania, the quality of collected ICT equipment does not allow a further lifecycle. In this case, used equipment can be sourced from other countries such as Germany, where supply exceeds regional demand. With regard to industrial networks, international cooperation between collectors (e.g. in western Europe), refurbishers (e.g. in eastern Europe) and retailers could be part of a European-wide strategy for value conservation, resource efficiency and employment.

The main economic barrier to ICT reuse networks is a lack of financial incentive for refurbishment companies (Becker, 2009). Low labour costs for the assembly of new ICT equipment compete with considerably higher labour costs for refurbishment (Beigl et al., 2009). Even in micro-enterprises, a burden has to be carried by the owner - by private capital or by precarious living conditions. It is therefore not economically viable to handle resources locally and to sell reuse products. The same applies to low-value products that could be reused in local symbioses, such as packaging material or grey water. This situation might be mitigated through tax relief for reused products. In addition, costs for raw materials and energy have typically increased, which might improve the economic feasibility of reuse.

Lack of transparency of product availability is another barrier to reuse. For example, ICT equipment in the storage rooms of companies and other organisations is not a controlled material stream. The implementation of radio frequency identification (RFID) technology or an inventory service might address this situation.

\subsection{Reuse best-practice guidance}

The successful development of technical, legal and financial guidance, and its incorporation into an accredited industry guideline, is a major achievement in terms of facilitating the reuse of ICT hardware. This guidance will provide authoritative support for reuse entrepreneurs faced with fundamental decisions when starting a reuse business. In addition, OEMs, retailers and ICT consultant firms that are considering an expansion of their economic activities towards refurbishment and reuse have been provided with reliable information.

The economic cost assessment revealed and quantified a highly relevant success factor for an enhancement of the reuse ICT sector. It is clear that time spent on refurbishing used ICT 
equipment determines whether those activities are economically feasible in comparison with producing new equipment.

\subsection{Transferability of the ReUse ICT network concept to other product categories}

This case study has demonstrated that the reuse of products and selected industrial residues is worthwhile in terms of reducing GHG emissions, enabling resource recovery and socioeconomic development. However, in both cases (the reuse of ICT products and resource conservation of wood offcuts) implementation of a cyclical resource flow is challenging from an economic standpoint. Even though scrap wood can be sourced free of charge, Lotta Rest furniture products are economically non-competitive compared with staple articles produced by large national or international companies. This is mainly due to relatively high local (EU) wages and the maintenance of reuse logistics in Germany compared with relatively low costs of production and shipping from outside the EU. This study has also demonstrated that some used ICT products (e.g. mobile phones) are unlikely to be exchanged by means of any platform that does not allow auctioning.

\subsection{Transferability of the ReUse ICT network concept to other regions}

There is potential to transfer the concept to other EU countries, but local conditions are likely to dictate success (or otherwise). In a relatively developed EU country such as Austria, only a small quantity of used ICT products is collected and refurbished for reuse. Transferring the RXP for ICT products to Austria is feasible as long as it supports the sales of usable products from Austria to other countries. Interested buyers in other countries (e.g. Hungary, Romania, Serbia) would have to be attracted in order to generate a market for such products. This perspective offers a realistic and financially viable potential for socioeconomic projects, small businesses and private citizens to offer their products to second users in other countries over the RXP.

The transferability and adoption of the business concept for a less developed EU country such as Romania also has good prospects; according to Erste Group Bank AG, growth for ICT sales in 2011 was $11 \cdot 3 \%$ and the forecast for 2012 was $12 \cdot 7 \%$ (Erste, 2011). Increased sales of new EEE in Romania imply greater collection of used EEE and a rise in the quality of collected EEE. Thus, remanufacturing of products will become more attractive to companies and will require less effort. The RXP is considered a vital tool for accelerating and structuring this development.

\section{Conclusions and recommendations}

This Zerowin case study has demonstrated that it is possible and in many cases economically viable - to increase the reuse stream of ICT equipment and to extend the activities of the
ReUse ICT network from a regional to European level. The expectation of doubling the amounts of traded appliances within the network was greatly exceeded. The RXP enables additional business opportunities through clustering of reuse firms in an industrial network and allows regional transfer of the ReUse ICT concept, the inclusion of further product categories and additional service offers (e.g. take-back, service instead of sales).

ICT reuse networks have an important role in terms of

- developing a quality control scheme and label

developing technical guidelines for the refurbishment process and a marketing concept for broad orientation of reuse companies and start-ups

designing and developing an RXP that combines different purchase options, products and materials for reuse and recycling (or a user group within an existing platform)

v promoting and lobbying for reuse

making high-level refurbishment and reuse more accepted in European society.

Reusing goods based on defined criteria is, in many cases, economically attractive and ecologically necessary, and makes sense for an inclusive society. Reuse networks deliver options for smart interlinkage of economic activities, resource protection, waste prevention and promising employment.

Further development of ICT reuse networks in Europe is possible and preferable with regard to ecological, social and economic considerations. A resolute European reuse and recycling strategy would help to save resources - primarily raw materials, but also water and energy. The European waste hierarchy provides an adequate resource utilisation and recovery framework for the consideration of ICT products. It will, however, be necessary to overcome technological and economic barriers by concerted measures such as establishing regional and international reuse networks and introducing financial incentives for reuse businesses. By aiming at value conservation through greater reuse activities in Europe, this is prerequisite to creating business opportunities in this sector.

In principle, the ReUse ICT network concept is transferable to other industrial sectors. Its economic feasibility depends on several factors that will have to be quantified individually, for example

logistical factors (transportation, storage, refurbishment/ repair, resale channels, etc.)

condition and value of the products

kinds of service offered (sale, rental, service)

costs of manufacturing a new product

innovation cycles. 
Other areas that require further development include

logistical aspects: value-conserving collection and transportation facilities

technical aspects: automatic identification systems (barcodes, RFID) for efficient processing of product streams within industrial networks

- product design: design for reuse and resource efficiency

- legal aspects: warranty prolongation and other instruments that could promote high-quality, reusable long-life products

sustainability: quantification of the potential of reuse with respect to GHG emissions and depletion of natural resources

- educational aspects: promotion of consumers' environmental conscientiousness.

These findings are highly relevant to ongoing international discussions on resource conservation, producer responsibility, waste entrepreneurship and the management of WEEE.

\section{Acknowledgement}

The research leading to these results received funding from the European Community's Seventh Framework Programme (FP7/2007-2013) under grant agreement no. 226752.

\section{REFERENCES}

Becker F (2009) ReUse-Networks - a contribution to a zero waste strategy. In Lechner, P (ed.) (2009) Prosperity Waste and Waste Resources. Proceedings of 3rd BOKU Waste Conference on Prosperity Waste and Waste Resources, Vienna, Austria. April 15-17. Vienna: OKU-University of Natural Resources and Applied Life Sciences, pp. 161-170. Beigl P, Pertl A, Scherhaufer S and Obersteiner G (2009) WP7
Workshops. Presentation at 2nd Zerowin General Meeting, Bilbao, Spain.

Curran T and Williams ID (2012) A zero waste vision for industrial networks in Europe. Journal of Hazardous Materials 207-208: 3-7.

Dünnwald R (2012) Management von IKT-Materialströmen an der Brandenburgisch Technischen Universität Cottbus. Student project report, Brandenburg University of Technology (available in German from Umweltanalytische Produkte $\mathrm{GmbH})$.

EAK (Elektroaltegeräte Koordinierungsstelle Austria GmbH) (2011) Tätigkeitsbericht 2011. EAK, Vienna, Austria (in German).

EC (European Commission) (2010) Critical Raw Materials for the EU: Report of the Ad-hoc Working Group on Defining Critical Raw Materials. EC, Brussels, Belgium.

Erste (Erste Group Bank AG) (2011) IT Industry Growth to Propel 2012 Economic Development in Central and Eastern Europe. See http://www.erstegroup.com/en/Press/Press-Releases/ Archive/2011/12/13-1/EN Research-Zentral-Osteuropa (accessed 12/04/2013).

HOP (Heise Online Publishing) (2013) Gartner erwartet 2012 nur 368 Millionen verkaufte PCs und Notebooks. See http:// www.heise.de/ct/meldung/Gartner-erwartet-2012-nur-368Millionen-verkaufte-PCs-und-Notebooks-1468157.html (accessed 03/04/2013) (in German).

Kuehr R and Williams E (2007) Computers and the Environment: Understanding and Managing their Impacts, 2nd edn. Kluwer, Dordrecht, Netherlands.

N24 (2013) Zahl der weltweit verkauften Computer 2009 gestiegen. See http://www.n24.de/news/newsitem_5756340. html (accessed 12/02/2013) (in German).

Öko-Institut (2011) Study on Rare Earths and their Recycling. Öko-Institut, Darmstadt, Germany, Final report for The Greens/EFA Group in the European Parliament.

\section{WHAT DO YOU THINK?}

To discuss this paper, please email up to 500 words to the editor at journals@ice.org.uk. Your contribution will be forwarded to the author(s) for a reply and, if considered appropriate by the editorial panel, will be published as discussion in a future issue of the journal.

Proceedings journals rely entirely on contributions sent in by civil engineering professionals, academics and students. Papers should be 2000-5000 words long (briefing papers should be 1000-2000 words long), with adequate illustrations and references. You can submit your paper online via www.icevirtuallibrary.com/content/journals, where you will also find detailed author guidelines. 